\title{
Нестандартные ситуации в хирургии осложненных юкстапапиллярных язв
}

\author{
E. N. SHEPETKO, A. E. SHEPETKO, V. V. EFREMOV, D. A. HARMASH, D. A. STRUMENSKYI, YU. S. KOZAK
}

National Medical University by A. A. Bohomolets

NON-STANDARD SITUATIONS IN SURGERY OF COMPLICATED UXTAPAPILAR ULCERS

\begin{abstract}
В статье проанализированы результаты лечения 270 пациентов, оперированных по поводу осложнённых постбульбарных (ПБЯ) (220 больных) и юкстапапилляных язв (ЮПЯ) (50 больных).

The article analyzes the results of treatment of 270 patients operated because of complicated postbulbar (220 patients) and uxtapapilar ulcers (50 patients).
\end{abstract}

Постановка проблем и анализ последних исследований и публикаций. Хирургические вмешательства при осложненных постбульбарных (ПБЯ) и околососочковых (юкстапапиллярных) язвах (ЮПЯ) сопровождаются достаточно весомым количеством разнообразных послеоперационных осложнений, таких, например, как послеоперационный панкреонекроз, возникающий у 8,4 \% пациентов, а послеоперационная летальность при осложненных ЮПЯ достигает $28 \%$ (Черноусов А. Ф. и соавт., 1987; Seicaru T., 1980; Yoshiya K. et al., 1985; Посмелов В. С., 1997; Курбанов К. М., 1999; CotirletA. et al., 1997; Велигоцкий Н. Н., 2009).

Это обусловлено тем, что выполнение ургентных оперативных вмешательств при гигантских каллезных пенетрирующих юкстапапиллярных язвах сопряжено с чрезвычайным риском ятрогенного повреждения билиарных и панкреатических протоков (Жерлов Г. К. и соавт., 2001; Лубянский В. Г., Насонов С. В., 2001; Фомин П. Д. и соавт., 2005; Хмельницький С. Й., 2010; Козак И. А. и соавт., 2011; Spynu A. V. et al., 1997).

Такие катастрофические интраоперационные осложнения ставят жизнь больного на грань, когда хирургу очень сложно выбрать рациональный путь дальнейшего выполнения этапов оперативного вмешательства (Козак И. А. и соавт., 2005, 2011; Суходоля А. И. и соавт., 2007). Особенно тяжело избрать вариант и схему относительно безопасного, но нестандартного реконструктивного оперативного вмешательства, основной целью которого является снижение риска возникновения фатальных послеоперационных осложнений.
Сложность проблемы заключается еще и в том, что с такой локализацией язвы и ее осложнениями хирурги разной квалификации и способностей встречаются в самый неблагоприятный и неожиданный момент. Как правило, оперативное вмешательство заканчивает хирург высокой квалификации, вызванный в клинику на операцию. Но это возможно в больших городских и областных центрах, тогда как в районных больницах не всегда удается своевременно получить консультацию и участие в операции высококвалифицированного хирурга. Поэтому способы оперативных вмешательств при осложненных ЮПЯ, направленные на снижение количества послеоперационных осложнений и летальности, нуждаются в дальнейшей разработке и усовершенствовании.

Материал и метод . Анализу подвергнуты 270 пациентов, оперированных по поводу осложненных постбульбарных (ПБЯ) (220 больных) и юкстапапиллярных язв (ЮПЯ) (50 больных).

1 группа - больные с осложненной залуковичной (постбульбарной) язвой (ПБЯ). Залуковичной (постбульбарной) язвой считалась язва, расположенная на расстоянии не меньше 3 см от пилорического жома. Группа составила 220 больных с осложненными язвами.

2 группа - больные с юкстапапиллярной локализацией язвы. Юкстапапиллярная (околососочковая) язва (ЮПЯ) - язва, находящаяся в непосредственной близости от БДС или вовлекающая его в язвенный процесс. Вторая группа составила 50 ЮПЯ, осложненных кровотечением, перфорацией, пенетрацией, стенозом или их сочетанием. 
Предложена модифицированная классификация осложненных ЮПЯ.

I. Супрапапиллярная язва - язва, расположенная проксимальнее (выше) БДС, так что между нею и БДС остается мостик слизистой не меньше 0,5 см и не больше 1 см.

II. Парапапиллярная язва - язва, расположенная на уровне БДС справа или слева на расстоянии не меньше 0,5 см.

III. Папиллярная язва - расположенная в зоне БДС с его частичным вовлечением.

IV. Гигантская папиллярная язва со значительной деструкцией БДС, так что визуализируются отдельно устья желчного и панкреатического протока.

V. Инфрапапиллярная язва - расположенная дистальнее (ниже) БДС не меньше чем на 0,5 см.

VI. Контрпапиллярная язва - расположенная напротив БДС на противоположной стенке ДПК.

Резул тат исследований и их обсуждение. Особенностью оперативного вмешательства по поводу осложненной ЮПЯ является уточнение расположения дистального края кратера язвы относительно БДС при раскрытом просвете ДПК. После введения бранш крючков Фарабефа в просвет ДПК удается увидеть БДС, который, как правило, оказывается, расположен на расстоянии 0,5-0,6 см от дистального края супрапапиллярной язвы. Этот момент является важнейшим на этом этапе оперативного вмешательства. В дальнейшем выполняют ушивание культи ДПК при супрапапиллярной язве с использованием прецизионной техники и атравматического шовного материала. Первый ряд слизисто-подслизистых швов может быть наложен узелками внутрь просвета атравматической иглой (викрил, дексон, максон, PDS) с нитью 3,0. Последующее закрытие просвета культи с наложением второго ряда швов может осуществляться традиционными методами или по разработанной методике (Способ ушивания культи двенадцатиперстной кишки при острокровоточащих перфоративных стенозирующих околососочковых дуоденальных язвах (Патент Украины № 16770, 2006)).

Сущность методики заключается в том, что после иссечения краев ЮПВ и предшествующего транспапиллярного дренирования холедоха с выведением управляемого дренажа трансдуоденально наружу на брюшную стенку через прокол в вертикальной части ДПК ушивание культи кишки осуществляют в несколько этапов. Накладывают первый ряд узловых швов узелками внутрь просвета атравматической нитью с последующим наложением двух полукисетных швов по линии предыду- щего шва, формируя таким образом “улитку" с последующим проведением и завязыванием ряда узловых поперечных вертикальных гофрирующих швов с подхватыванием капсулы головки поджелудочной железы.

Приводим пример клинического случая применения разработанного способа.

1. Больной Р., 31 год (и. б. № 10052), поступил в клинику 12.07.01 г. по поводу желудочно-кишечного кровотечения с признаками перитонита. Язвенного анамнеза нет. При рентгенологическом исследовании выявлен свободный газ под куполом диафрагмы. При фиброгастродуоденоскопии в просвете желудка около 300 мл содержимого типа “кофейной гущи", в дистальном отделе ДПК выявлена язва 3 см в диаметре с тромбированными сосудами на дне кратера и стенозированием просвета ДПК в этом месте. 12.07.01г. экстренная операция в связи с перфорацией острокровоточащей стенозирующей дуоденальной язвы. Обнаружена каллёзная пенетрирующая в печеночно-двенадцатиперстную связку и поджелудочную железу ЮПЯ с инфильтратом 5х5 см и перфоративным отверстием $0,7 \times 0,8$ см, а также субкомпенсированным дуоденальным стенозом с расширением полости желудка. Язва глубоко пенетрировала в головку поджелудочной железы и стенку желчного пузыря. При разделении спаечных наслоений и мобилизации ДПК по Кохеру вскрыт просвет желчного пузыря в зоне пенетрации гигантской юкстапапиллярной язвы. При дуоденотомии по уровню стенозирования в постбульбарной части ДПК обнаружено, что дистальный край язвы находился на расстоянии 0,3 см от БДС. После иссечения краев ЮПЯ осуществлено предварительное транспапиллярное дренирование холедоха с выведением дренажа трансдуоденально наружу на брюшную стенку через прокол в вертикальной части ДПК. Ушивание культи ДПК осуществлено путем наложения первого ряда узловых швов узелками внутрь просвета атравматичной нитью (викрил $3 / 0$ ) с последующим наложением двух полукисетных швов по линии предыдущего шва, формируя таким способом культю, с последующим проведением и завязыванием ряда узловых поперечных вертикальных гофрирующих швов. Стенку культи ДПК подшили к капсуле головки поджелудочной железы. Затем выполнили селективную ваготомию с эзофагофундопликацией и антрумэктомию с гастроеюноанастомозом по Гофмейстеру-Финстереру, холецистэктомию. Послеоперационный период протекал без осложнений. Через 16 дней удалили транспапиллярный наружный управляемый дренаж. Срединная рана зажила первичным натяжением. 
Больной выписан в удовлетворительном состоянии 30.07.01г. Осмотрен через два года, жалоб не предъявлял, работал по специальности.

Юкста- или парапапиллярное расположение кровоточащей язвы при неизмененном пилорическом жоме позволяет выполнить сегментарную или заднюю мостовидную (субциркулярную) дуоденопластику на 3/4-4/5 периметра, сшив заднюю стенку duodenum прецизионным однорядным швом, а переднюю - двухрядным.

Такой вариант операции возможен, когда язва не относится к гигантской и от дистального края кратера до БДС остается 3-5 мм ткани стенки ДПК. Для профилактики послеоперационного панкреатита и развития механической желтухи вследствие отека БДС применяем транспапиллярное трансдуоденальное наружное управляемое дренирование холедоха в сочетании с дуоденопластикой (методика А) (Патент Украины № 31820A, 2000).

С применением указанного способа оперирован один больной с околососочковой кровоточащей дуоденальной язвой с пенетрацией ее в головку поджелудочной железы. Операция выполнена на высоте кровотечения с благоприятным исходом пациент выздоровел и был выписан без осложнений под наблюдение хирурга поликлиники.

Кроме того, осуществление гемостаза прошиванием краев и дна кратера такой язвы опасно в связи с возможностью прошивания БДС, а также высокой вероятностью возникновения послеоперационного панкреатита. В то же время, использование часто применяемых методов операций, связанных с вмешательством на язве в виде иссечения ее краев или выведения за пределы кишечного канала, приводит к таким опасным осложнениям, как:

- выведение из просвета кишечного канала кратера язвы, расположенной вблизи БДС, связано с угрозой его повреждения (травматизации, прошивания);

- высокий риск развития недостаточности швов по верхнему контуру пилоропластики;

- большая угроза развития послеоперационного панкреатита.

Учитывая опасность развития вышеперечисленных послеоперационных осложнений, представляется возможным применить разработанную методику хирургического лечения околососочковых острокровоточащих язв двенадцатиперстной кишки (Патент Украины № 22940А, 1998), которая позволяет снизить риск указанных послеоперационных осложнений и послеоперационную летальность.

Сущность ее состоит в выполнении СПВ, поперечной пилородуоденопластики с иссечением краев язвы, транспапиллярном дренировании холе- доха через зону язвы, расположенной вблизи БДС, трансдуоденальном выведении наружного управляемого дренажа холедоха, вворачиванием краев стенки ДПК с тампонированием ею кратера язвы и наложением гофрирующих швов по верхнему контуру пилородуоденопластики с подхватыванием элементов брюшины, гепатодуоденальной связки и стенки желчного пузыря.

Приводим клинический пример конкретного выполнения предложенного способа.

1. Больной П., 27 лет (и. б. № 9660), переведен в клинику 27.09 .95 г. из гастроэнтерологического отделения, где находился на лечении с 29.08.95 г. по поводу хронической каллёзной язвы двенадцатиперстной кишки в связи с развившимся острым желудочным кровотечением. Экстренное эндоскопическое исследование указало на наличие язвы 2 см в диаметре с тромбированными сосудами на дне ее кратера. 27.09.95 г. выполнена операция, во время которой выявлена язва в дистальном отделе луковицы размерами 2,5×2,5 см, пенетрирующая в поджелудочную железу и гепатодуоденальную связку. После выведения язвы за пределы кишечного канала на уровне дистального края язвенного кратера обнаружен БДС. Выполнено транспапиллярное дренирование холедоха управляемым дренажем, проведенным трансдуоденально на границе вертикальной и нижне-горизонтальной части ДПК, с последующим выведением его наружу через прокол брюшной стенки. Произведена пилородуоденопластика с тампонированием кратера язвы лоскутками стенки ДПК, наложением полукисетных гофрирующих швов с подхватыванием элементов серозной оболочки гепатодуоденальной связки и серозной оболочки стенки желчного пузыря. Выполнена интраоперационная чрездренажная холангиография - заполнилась билиарная протоковая система и дистальная часть главного панкреатического протока с поступлением контраста в двенадцатиперстную кишку. Затем произведена СПВ с эзофагофундопликацией, операция Стронга. Через 16 дней после операции удален транспапиллярный дренаж. Больной выписан 19.10.95 г. в удовлетворительном состоянии для дальнейшего амбулаторного лечения.

По предложенному способу оперировано двое больных по поводу острокровоточащей ЮПЯ с благоприятным исходом и выздоровлением. Способ является более эффективным в хирургическом лечении острокровоточащих околососочковых язв ДПК, позволяет снизить частоту послеоперационных осложнений (недостаточность швов пилоропластики, механическая желтуха, послеоперационный панкреатит) и послеоперационную летальность. 
При папиллярных осложненных ЮПЯ, когда не удается выполнить органосохраняющую операцию (ДП или ПП) в сочетании с ваготомией, может быть выполнена реимплантация БДС в ДПК с иссечением краев ЮПЯ по разработанной методике В (Патент Украины № 23123А, 1998) или методике Г (дополнительно включает выполнение папиллосфинктеропластики) (Патент Украины № 52598, 2010).

Сущность методики В состоит в иссечении краев язвы, транспапиллярном наружном управляемом дренировании холедоха, ушивании культи ДПК, выполнении АЭ с ваготомией, формировании впередиободочного гастроеюноанастомоза на длинной петле с Брауновским соустьем и проведении трансеюнально, через приводящую петлю кишки, управляемого наружного транспапиллярного дренажа холедоха.

По методике В оперирован один больной с положительным результатом.

Приводим пример клинического применения предложенного способа.

1. Больной Б., 42 года (и. б. №14789), доставлен в клинику 12.12 .92 г. по поводу острокровоточащей язвы ДПК. Эндоскопическое исследование обнаружило дуоденальную язву в залуковичной ее части с выраженной рубцовой деформацией, стенозированием ДПК и остановившимся кровотечением. 15.12.92 г. возник рецидив кровотечения, и больной был немедленно оперирован. Во время операции обнаружена стенозирующая каллёзная залуковичная язва. При попытке выполнить пилоропластику и вывести язву за пределы пилородуоденального канала обнаружен БДС на дне кратера язвы. Выполнено транспапиллярное дренирование холедо$\mathrm{xa}$, атипичное ушивание культи двенадцатиперстной кишки, укрывание культи ДПК стенкой приводящей петли тощей кишки после антрумэктомии и формирование анастомоза культи желудка с длинной петлей тощей кишки и брауновским соустьем, проведением трансеюнального наружного транспапиллярного дренажа холедоха. Затем выполнена селективная ваготомия. Наложена дополнительно холецистостома в виде страховочного дренажа желчевыводящих путей. Послеоперационный период проходил без осложнений. Транспапиллярный дренаж холедоха и холецистостомический удалены на 10-й и 12-й день. Выписан через 14 дней после операции в удовлетворительном состоянии.

При папиллярных язвах больших размеров для уменьшения риска послеоперационных осложнений применялась разработанная методика реимплантации БДС в ДПК с выполнением папиллосфинктеропластики, транспапиллярного трансдуоденаль- ного наружного управляемого дренирования холедоха в сочетании с антрумэктомией и селективной ваготомией (методика Г) (Патент Украины № 52598,2010 ).

В тех случаях, когда при мобилизации ДПК и выведении осложненной дуоденальной язвы обнаруживали ее папиллярное расположение, разработан способ реимплантации БДС в тощую кишку, выключенную по Брауну (методика Д) (Патент Украины № 47638, 2010).

Сущность методики заключается в осуществлении антрумэктомии, ушивании культи ДПК ниже уровня БДС и язвы, транспапиллярном дренировании БДС с выведением дренажа трансеюнально наружу после реимплантации зоны БДС в петлю тощей кишки и перитонизации линии швов стенкой приводящей петли тощей кишки.

В тех случаях, когда при гигантских папиллярных язвах со значительной деструкцией БДС визуализируются раздельно устья холедоха и панкреатического протока, может быть выполнена методика реимплантации БДС в тощую кишку, выключенную по Брауну, с раздельным транспапиллярным наружным управляемым дренированием холедоха и панкреатического протока, разработанная в клинике (методика Е) (Патент Украины № 23125A, 1998).

Разработанный способ операции заключается в выполнении антрумэктомии, ушивании культи ДПК ниже уровня БДС и язвы, транспапиллярном раздельном дренировании БДС и главного панкреатического протока с выведением управляемых дренажей трансеюнально наружу после реимплантации области БДС и главного панкреатического протока в петлю тощей кишки с перитонизацией линии швов стенкой приводящей петли тощей кишки.

Приводим клинический пример применения разработанного способа.

1. Больная Д., 57-ми лет (и. б. № 3748), поступила в клинику 23.03.95 г. по поводу острого холецистита, остановившегося острого язвенного кровотечения и оперирована в экстренном порядке. Во время операции обнаружен флегмонозный калькулезный холецистит. Выполнена холецистэктомия от шейки. При ревизии пилородуоденальной зоны обнаружена низко расположенная язва ДПК диаметром 2,5 см. При выведении язвы за пределы кишечного канала обнаружено папиллярное ее расположение с раздельным впадением главного панкреатического протока на расстоянии 1,3 см от устья большого дуоденального сосочка на дне кратера гигантской каллёзной язвы. Стенка кишки пересечена ниже БДС и места впадения главного панкреатического протока по краю гигантской 
язвы, культя ушита трехрядными швами. Выполнены антрумэктомия и стволовая ваготомия. Сформирован гастроеюноанастомоз на короткой петле, затем взята отводящая петля тощей кишки, проведена позадиободочно, область БДС и главного панкреатического протока реимплантирована в нее, выполнено транспапиллярное наружное дренирование холедоха и раздельно вирсунгового протока с трансеюнальным выведением дренажей в виде наружных управляемых. Перитонизация линии швов серозной оболочкой приводной петли, формирование энтероэнтероанастомоза, дренирование брюшной полости. Послеоперационный период без осложнений. Управляемые дренажи удалены 12.04.1995 г. Выписана для амбулаторного лечения 17.04.1995 г. Осмотрена через год. Чувствовала себя хорошо, прибавила в весе 4 кг. Затем осмотрена и обследована через 12 лет. Рецидива язвы, патологических синдромов, связанных с оперативным вмешательством, не выявлено.

При осложненных гигантских папиллярных и юкстапапиллярных дуоденальных язвах, при значительной вероятности интраоперационного повреждения БДС, а также при гигантских язвах со значительными деструктивными изменениями, которые затрагивают смежные зоны, применялась разработанная методика Ж (Патент Украины № 23126A, 1998).

Сущность методики состоит в выполнении реимплантации БДС в ДПК, папиллосфинктеропластики, трансдуоденального наружного управляемого ТПДХ, антрумэктомии с селективной ваготомией, ушивании культи ДПК над зоной околососочковой язвы, перитонизации ушитой культи стенкой приводящей петли тощей кишки.

Приводим клинические примеры выполнения операции по разработанному способу.

1. Больной Ч., 22-х лет (и. б. № 2872), поступил в клинику 6.03.96 г. по поводу тяжелого язвенного кровотечения. Язвенный анамнез 8 лет. При поступлении Нв - 75 г/л. Эндоскопическое исследование указало на наличие язвы 2,0 см в диаметре с тромбованными сосудами на дне язвы. Во время операции (7.03.96 г.) обнаружена стенозирующая пенетрирующая в головку поджелудочной железы и гепатодуоденальную связку дуоденальная язва, субкомпенсированный стеноз выхода из желудка. Попытка выполнить пилорускорригирующую пилоропластику оказалась напрасной. Заподозрено повреждение БДС при мобилизации стенки двенадцатиперстной кишки, когда на уровне дистального края кратера язвы обнаружено устье БДС. Выполнена папиллосфинктеропластика, реимплантация зоны БДС в ДПК, транспапиллярное трансдуоденальное наружное управляемое дренирование холедоха, атипичное ушивание культи ДПК, селективная ваготомия и антрумэктомия с анастомозом на длинной петле и Брауновским соустьем, дополнительная перитонизация зоны ушитой культи с реимплантированным БДС серозной оболочкой стенки приводящей петли тощей кишки, холецистэктомия, наружное дренирование холедоха по Пиковскому в виде страховочного дренажа (билиарное дренирование). В послеоперационном периоде больной получил три курса лечения сандостатином. Управляемые дренажи удалены через 2,5 недели. 8.04.96 г. выписан из клиники в удовлетворительном состоянии. Осмотрен и обследован через 2 месяца. Жалоб не предъявлял, прибавил в весе 4 кг. При контрольной ФЭГДС анастомоз шириной 2,5 см, умеренно выраженный гастрит культи желудка.

Обследован через 14 лет после операции (больной Ч., 36 лет). Жалоб на момент обследования нет. Масса тела - 104 кг. Работает по специальности (менеджер). УЗИ от 23.12.2010 г. - УЗ-признаки хронического панкреатита. ФЭГДС от 26.12.2010 г. - признаки хронической гастропатии с атрофией слизистой культи желудка. Нр-тест (иммунологический) 27.12.2010 г.: Ig A - 2,9455 - полож.; Ig G - 20,5 - полож. ДНК Нр, ПЦР - не выявлено. Пациенту амбулаторно назначена эрадикационная терапия. Через 2,5 месяца констатирована эффективная эрадикация по данным дыхательного теста.

В предложенном способе сделана попытка реализовать новый подход в лечении околососочковых гигантских язв, осложненных кровотечением, при возникновении нестандартной интраоперационной ситуации, связанной с вовлечением БДС в язвенный процесс или его ятрогенном повреждении.

При осложненной гигантской папиллярной язве, сопровождающейся значительной деструкцией БДС, или интраоперационном его повреждении, был разработан способ реимплантации БДС в выключенную по Ру петлю тощей кишки с папилосфинктеропластикой и транспапиллярным трансеюнальным наружным управляемым дренированием холедоха (методика 3) (Патент Украины № 14799 , 2006), который снижает послеоперационную летальность и предотвращает тяжелые послеоперационные осложнения, улучшает функциональные результаты операции.

Сущность способа состоит в том, что после иссечения краев юкстапапиллярной язвы и ушивания культи ДПК ниже язвы, папиллосфинктеропластики, выполняют реимплантацию БДС в тощую 
кишку, выключенную по Ру, путем создания в конечной части выключенной по Ру петли тощей кишки двойной концевой петли кишки сшиванием ее стенки серо-серозными швами с подковообразной энтеротомией и последующей реимплантацией БДС в эту зону, формированием муфтообразного инвагинационного панкреатоеюноанастомоза с транспапиллярным трансеюнальным наружным управляемым дренированием холедоха. Заканчивают операцию селективной ваготомией с антрумэктомией и гастроеюноанастомозом по Гофмейстеру-Финстереру.

Пример конкретного выполнения предложенного способа операции.

1. Больной М., 41 год (и. б. № 11936), поступил в клинику 2.09.03 г. по поводу желудочно-кишечного кровотечения. Язвенный анамнез 3 года. При ФЭГДС в просвете желудка около 300 мл содержимого типа "кофейной гущи", в дистальном отделе двенадцатиперстной кишки обнаружена язва 2,0 см под фибрином с тромбированными сосудами на дне. 5.09.03 г. операция в отсроченном периоде. Обнаружена каллезная пенетрирующая в печеночно-двенадцатиперстную связку и поджелудочную железу юкстапапиллярная язва двенадцатиперстной кишки диаметром 2,5 см. Субкомпенсированный дуоденальный стеноз с расширением просвета желудка, долихосигма. При дуоденотомии по уровню стенозирования в постбульбарной части двенадцатиперстной кишки установлено, что язва захватывает верхнюю часть БДС, а стенка кишки в этом месте значительно рубцово изменена, что сделало невозможным выполнение реимплантации БДС в ДПК. Поэтому выделена стенка ДПК и ушита ниже (дистальнее) язвы и БДС. Затем мобилизована тощая кишка на сосудистой брыжеечной аркаде после пересечения ее на расстоянии 60 см от дуоденоеюнального перехода. Дистальный конец кишки ушит, после чего сформирована двойная концевая петля тощей кишки путем сшивания ее серо-серозными швами на протяжении 5-6 см; произведена подковообразная энтеротомия концевой петли тощей кишки. После папиллосфинктеропластики выполнено транспапиллярное дренирование холедоха, зону БДС реимплантировали в двойную концевую петлю тощей кишки с наложением муфтообразного инвагинационного панкреатоеюноанастомоза двухрядным швом с выведением транспапиллярного дренажа холедоха трансеюнально наружу в виде управляемого после наложения кисетного шва на стенку кишки с подшиванием ее к париетальной брюшине передней брюшной стенки. На расстоянии 50-60 см от зоны реимплантации сформиро- ван энтероэнтероанастомоз по Ру. Выполнена селективная ваготомия и антрумэктомия с гастроеюноанастомозом на расстоянии 30-40 см от энтероэнтероанастомоза по Ру. Выполнена мезосигмопликация по Гагенторну. Послеоперационный период проходил без осложнений. Осмотрен через полтора года. Жалоб не предъявлял, работал по специальности.

При осложненных кровотечением папиллярных язвах после остановки кровотечения и обнаружении язвы с частичным разрушением БДС по правому или левому контуру возникает возможность выполнения органосохраняющей операции с одновременным вмешательством на язве в зоне ампулы БДС и слияния желчного и панкреатического протоков.

Выполняют мобилизацию ДПК по Кохеру и дуоденотомию в зоне язвенного дефекта или постбульбарного дуоденального стеноза. Обнаруживают язву в зоне БДС с частичной его деструкцией. Отсутствие значительной деструкции в зоне БДС позволяет, тщательно мобилизовав стенки, осуществить гемостаз в зоне язвы под визуальным контролем, а затем выполнить папиллосфинктеротомию с папиллосфинктеропластикой и вирсунгопластикой.

Транспапиллярное дренирование холедоха после папиллосфинктеропластики выполняется при опасности последующего рубцевания в этой зоне. Чаще всего без него можно обойтись, если деструктивные изменения не так выражены и язва не принадлежит к гигантским папиллярным язвам с деструкцией билиарной и панкреатической протоковых систем. При необходимости выполняют холецистэктомию с дренированием холедоха по Пиковскому. Затем выполняют селективную проксимальную ваготомию с эзофагофундопликацией, желательно с применением ультразвукового скальпеля, и операцию Стронга с низведением дуоденоеюнального перехода, которая обеспечивает нормализацию интрадуоденального давления, снижая риск дуоденобилиарного и дуоденопанкреатического рефлюкса (методика И) (Патент Украины № 48760, 2010).

При обнаружении контрпапиллярной или инфрапапиллярной язвы, когда расположение ее позволяет выполнить органосохраняющую операцию, целесообразным является выполнение мостовидной (субциркулярной) или сегментарной (циркулярной) дуоденопластики с дополнением ее СПВ или комбинированной ваготомией при продолжительном язвенном анамнезе у пациента и значительных морфологических изменениях в зоне язвы. 
В случае инфрапапиллярной язвы может быть применена методика с реимплантацией БДС в тощую кишку, выключенную по Ру с трансеюнальным ТПДХ (методика 3) или дуоденопластика с папиллосфинктеротомией и ТПДХ, дополненная СПВ (методика А).

Всего ранние послеоперационные осложнения (РПО) возникли у 26 из 220 оперированных $(11,8 \%)$ по поводу осложненных ПБЯ, 13 \% РПО (15 пациентов из 115) в I периоде наблюдения (19831992 гг.) и 10,5 \% (11 больных из 105) - во II периоде (1993-2008 гг.).

При осложненных ЮПЯ ранние послеоперационные осложнения возникли за весь период наблюдения у 21-го из 50-ти больных (42\%); 66,6 \% осложнений возникло у больных, оперированных по поводу осложненных ЮПЯ в I периоде, а у 16-ти из 41-го пациента (39 \%) - во II периоде наблюдений. Во втором периоде наблюдений после внедрения разработанных методик оперативных вмешательств при околососочковых осложненных язвах, а также благодаря адекватным методам дренирования и послеоперационного ведения больных, послеоперационную летальность удалось снизить до $14,6 \%$, т. е. в 2,3 раза.

\section{СПИСОК ЛИТЕРАТУРЫ}

1. Симультанные органосохраняющие операции при осложненных формах язвенной болезни желудка и двенадцатиперстной кишки в сочетании с рефлюксом / Н. Н. Велигоцкий, А. Н. Велигоцкий, В. В. Комарчук [и др.] // Харківська хірургічна школа. - 2009. - № 4.1 (36). - С. 163-166.

2. Диагностика и хирургическое лечение постбульбарных язв двенадцатиперстной кишки / Г. К. Жерлов, О. Н. Фурсова, И. О. Гибадулина [и др.] // Вестник хирургии. -2001. - № 160 (1). - C. 21-24.

3. Козак I. О. Попередження інтраопераційних ускладнень при лікуванні хворих на зацибулинну виразку дванадцятипалої кишки : автореф. дис. на соискание учёной степени докт. мед. наук / I. О. Козак. - Вінниця, 2011. - 34 с.

4. Курбанов К. М. Хирургическое лечение постбульбарных язв, осложненных пенетрацией в головку поджелудочной железы / К. М. Курбанов // Хирургия. - 1999. - № 2. - С. 8-10. 5. Лубянский В. Г. Острый панкреатит после резекции желудка при низкорасположенных дуоденальных язвах / В. Г. Лубянский, С. В. Насонов // Хирургия. - 2001. - № 3. - С. 8-11. 6. Посмелов В. С. Хирургическое лечение постбульбарных язв двенадцатиперстной кишки / В. С. Посмелов, В. А. Кубышкин, И. А. Козлов // Хирургия. - 1997. - № 5. - С. 4-9. 7. Ускладнення хірургічного лікування "тяжких" виразок шлунка та дванадцятипалої кишки / А. І. Суходоля, І. О. Козак, О. О. Підмурняк [та ін.] // Клінічна анатомія та оперативна хірургія. - 2007. - Т. 6, № 4. - С. 16-18.

8. Технічні особливості реімплантації великого дуоденально-
В вод . 1. Технически сложные и трудоемкие оперативные вмешательства по разработанным методикам чаще всего носят вынужденный характер и преследуют две основные цели: вооружиться способами операций, которые позволяют выйти из критической интраоперационной ситуации, максимально использовав профилактические мероприятия в отношении развития тяжелых послеоперационных осложнений; снизить очень высокую для таких случаев послеоперационную летальность.

2. Чаще всего при неблагоприятном результате хирурги не склонны к тому, чтобы рассматривать причины неудач этих сложных ситуаций. Вместе с тем, отсутствие подробного анализа таких клинических случаев не может обогатить хирургический опыт и послужить основой для положительных сдвигов в этой проблеме. Открывая этот занавес, хирурги, основываясь на собственном опыте и опыте коллег, чаще отрицательном, подвергая его тщательному анализу, идут путем разработки новых тактических, оперативных приемов и способов реконструктивных операций. Это является ключевым моментом, который дает возможность надеяться, что в будущем эта сложная проблема будет решена.

го сосочка при ускладнених юкстапапілярних виразках / П. Д. Фомін, С. М. Шепетько, М. В. Щербина [та ін.] // Шпитальна хірургія. - 2005. - № 1. - С. 15-19.

9. Хмельницький С. Й. Хірургічна тактика при постбульбарних і юкстапапілярних виразках дванадцятипалої кишки, ускладнених механічною жовтяницею // Науковий конгрес "IV Міжнародні Пироговські читання", присвячений 200-річчю М. I. Пирогова : матер. XXII з'їзду хірургів України. - Вінниця, 2010. - Т. II. - С. 215-216.

10. Внелуковичные язвы двенадцатиперстной кишки / А. Ф. Черноусов, А. М. Ануфриев, А. М. Корчак [и др.] // Хирургия. - 1987. - № 5. - С. 42-47.

11. Complicated postbulbar duodenal ulcer: the characteristics of its diagnosis and surgical technic and management / A. Cotirlet, I. Ivan, R. Anghel [et al.] // Rev. Med. Chir. Soc. Med. Nat. Iasi. 1997. - Vol. 101(1-2). - P. 164-169.

12. Seicaru T. Postbulbar hemorrhagic ulcer / T. Seicaru, V. Gradinaru // Rev.Chir Oncol. Radiol. O.R.L. Oftalmol. Stomatol. Chir. - 1980. - Vol. 29(5). - P. 349-355.

13. Surgical treatment of postbulbar duodenal ulcer/A. V. Spynu, P. V. Buzhor, A. N. Organ, E. S. Livshits // Vestn. Khir. Im I. I. Grek. - 1990. - Vol. 144(1). - P. 35-37.

14. Surgical management of acute hemorrhagic postbulbar duodenal ulcer after a previous major surgical procedure / K. Yoshiya, Y. Ishikawa, J. Miura [et al.] // Jpn. J. Surg. - 1985. - Vol. 15(5). P. $348-354$. 